\title{
Converting biomass into efficient oxygen reduction reaction catalysts for proton exchange membrane fuel cells
}

\author{
Xingdong Wang, Jinjie Fang, Xuerui Liu, Xiangqian Zhang, Qingqing Lv, Zhaoxiang Xu, \\ Xuejiang Zhang, Wei Zhu ${ }^{*}$ and Zhongbin Zhuang
}

\begin{abstract}
It is urgent to develop low-cost but efficient oxygen reduction reaction (ORR) catalysts for the emerging clean energy devices of fuel cells based on proton exchange membrane. Herein, we report a facile method to covert the biomass of black fungus into an efficient ORR catalyst. The black fungus undergoes hydrothermal and pyrolysis processes to transform into carbon-based materials. The as-obtained BF-N-950 catalyst shows prominent ORR catalytic activities in both acidic and alkaline electrolytes with a half-wave potential reaching 0.77 and $0.91 \mathrm{~V}$, respectively. A membrane electrolyte assembly was fabricated with the as-obtained BF-N-950 as the cathode catalyst which shows a high peak power density of $255 \mathrm{~mW} \mathrm{~cm}^{-2}$. The study shows the potential of converting conventional biomass into low-cost ORR catalyst, which is promising for the fuel cell technology.
\end{abstract}

Keywords: biomass, oxygen reduction reaction, electrocatalysts, proton exchange membrane fuel cell

\section{INTRODUCTION}

Proton exchange membrane fuel cells (PEMFCs) can convert the chemical energy directli into electricity with the advantages of environmental friendliness, high power density, quick-start ability and low operating temperature $[1,2]$. In the PEMFCs, the oxygen reduction reaction (ORR) at the cathode requires $\mathrm{Pt}$ to accelerate the reaction, and the high price of Pt hampers the commercialization of the PEMFCs [3]. Thus, low-cost non-precious metal-based ORR catalysts are highly desired. Carbonbased materials have shown remarkable ORR activities in acidic electrolytes [4]. Although there is still a gap to the activity of $\mathrm{Pt}$, carbon materials become a prospective candidate to replace the noble catalyst [5]. The pristine carbon materials exhibit poor activity in the ORR process $[6,7]$, while after being doped with transition metals (e.g., Fe and Co) or nonmetals (e.g., N, P, S and B), they show enhanced ORR activity, due to the tuning effect triggered by the different electronegativity and atomic size of the dopants [6,8-10]. Especially, the Fe-N-C type materials have shown an ORR activity close to that of $\mathrm{Pt}$, and it is promising for PEMFCs $[11,12]$. The porphyrin like Fe- $\mathrm{N}_{4}$ sites were considered as the active sites for ORR [12]. This type of Fe-N-C material was synthesized by pyrolyzing metal porphyrin [13-16]. However, the porphyrin has relative high price. The syntheses of non-precious metal ORR catalysts from cheaper precursors, such as metal polyaniline complex and metal organic frameworks, have been reported [11,17-20]. Highly active ORR catalysts derived from low-cost precursors are still challenging [5].

Biomass can be used as carbon precursors, and it has the advantages of environmental friendliness, low cost and easy accessibility [21-23]. Some carbon-based ORR catalysts converted from biomass have been reported, including plant-based biomass (e.g., coconut and soybean shell, fruit peels, grass and seaweeds) and animal-based biomass (e.g., feathers, bones, blood, silk and hair) [21,23-28]. Liu et al. [29] converted peanut with dopant of vitamin B12, a biomolecule containing a cobalt atom, into an electrocatalyst for ORR in alkaline electrolyte, and a $\mathrm{Zn}$-air battery was fabricated by this biomass-derived catalyst. Guo et al. [28] developed a facile and cost-effective approach to synthesize nitrogen-doped carbon materials by calcining enoki mushrooms, which turned into a durable ORR catalyst. In 2015, Yuan's group [30] extracted chitin from shrimp, crab, crayfish and krill shells, and transformed it into ORR/oxygen evolution

State Key Lab of Organic-Inorganic Composites and Beijing Key Laboratory of Energy Environmental Catalysis, Beijing University of Chemical Technology, Beijing 100029, China

"Corresponding authors (emails: zhuwei@mail.buct.edu.cn (Zhu W); zhuangzb@mail.buct.edu.cn (Zhuang Z)) 
reaction (OER) bi-functional catalyst. However, these reported biomass-derived catalysts only show ORR activity in alkaline electrolyte, and the reports about biomass-derived highly active ORR catalysts in acidic environment and their performance in real PEMFCs are rare.

Black fungus is a common product in northeastern and southwestern China, and has large productivity and low price. The black fungus from different areas has similar compositions, which is rich in minerals (such as Fe, Table S1), protein, polysaccharide and vitamins (Table S2) $[31,32]$. Thus it could be a good precursor for the synthesis of carbon-based materials with Fe, N S and P doping [33]. In this paper, we report a facile synthetic strategy to convert the biomass of black fungus into a highly efficient ORR catalyst, and it shows an outstanding cell performance in PEMFCs. We successfully converted black fungus into Fe-N-C type materials through a hydrothermal process followed by pyrolysis. The rich Fe, N, $\mathrm{S}$ and $\mathrm{P}$ in black fungus lead to the homogeneous doping of the pyrolyzed carbon products. Additional nitrogen resource was added during the pyrolysis step to further enhance their ORR activity. The as-obtained biomassderived catalysts show high ORR activities in both acidic and basic electrolytes, with the ORR half-wave potential as high as 0.77 and $0.91 \mathrm{~V}$ in $0.1 \mathrm{~mol} \mathrm{~L}^{-1} \mathrm{HClO}_{4}$ and $\mathrm{KOH}$ electrolytes, respectively. A PEMFC membrane electrode assembly (MEA) was fabricated by using this material as the cathode catalyst, and it delivered a peak power density of ca. $255 \mathrm{~mW} \mathrm{~cm}^{-2}$. These results demonstrate that the highly active biomass-derived catalyst is promising for PEMFC applications.

\section{EXPERIMENTAL SECTION}

\section{Materials}

Dried black fungus (produced in northeastern China) was bought from local supermarket. Melamine, aqueous ammonia (25\%-28\%), urea, ethanol, $\mathrm{HCl}(36.5 \%)$ and $\mathrm{ZnCl}_{2}$ were received from Sinopharm Chemical Reagent co., ltd. Ketjen black EC600JD was supplied by Akzo Nobel. Nafion 211 membrane and nafion solution (D520, 5 wt\%) were purchased from DuPont Company. All chemicals and materials were used without any purification. Solutions were prepared with deionized water $(18.2 \mathrm{M} \Omega \mathrm{cm})$.

\section{Preparation of the BF-N-950 catalysts}

Dried black fungus $(3.0 \mathrm{~g})$ and water $(30 \mathrm{~mL})$ were loaded in a $50-\mathrm{mL}$ autoclave. Then the autoclave was placed in an oven at $180^{\circ} \mathrm{C}$ for $24 \mathrm{~h}$. After being cooled down to room temperature, the products were collected by filtration and washed with deionized water, and then dried in an oven for $12 \mathrm{~h}$. The dried materials were then ground into powder. Afterwards, $500 \mathrm{mg}$ of the powder was dispersed in a solution consisting of $500 \mathrm{mg}$ of urea, $6 \mathrm{~mL}$ of aqueous ammonia, $36 \mathrm{~mL}$ of ethanol and $94 \mathrm{~mL}$ of deionized water. The mixed dispersion was then stirred for $10 \mathrm{~h}$. Then the materials were collected by centrifugation and washed with deionized water. The products were dried by freeze drying for $24 \mathrm{~h}$. Subsequently, $300 \mathrm{mg}$ of the dried powder was ground with $300 \mathrm{mg}$ of $\mathrm{ZnCl}_{2}$, and then the mixture was transferred into a ceramic boat and placed in a tube furnace. A ceramic boat loaded with $1.5 \mathrm{~g}$ of melamine was placed at the upstream of the tube furnace. Then it was heated to $950^{\circ} \mathrm{C}$ in $\mathrm{N}_{2}$ atmosphere with a heating rate of $5^{\circ} \mathrm{C} \mathrm{min}{ }^{-1}$, and maintained at this temperature for $2 \mathrm{~h}$ before it was naturally cooled down. Then the obtained catalysts were collected and leached in acid $\left(1 \mathrm{~mol} \mathrm{~L}^{-1} \mathrm{HCl}\right)$ for $8 \mathrm{~h}$ at $80^{\circ} \mathrm{C}$, followed with washing by deionized water via filtration. The obtained catalysts were denoted as BF-N-950.

\section{Physical characterizations}

The morphologies of the as-prepared catalysts were studied by transmission electron microscopy (TEM, JEOL JEM1230) and scanning electron microscopy (SEM, Zeiss Supra 55). The microstructure was analyzed by high-resolution TEM (HRTEM, JEOL, JEM-2100). The energy dispersive spectra (EDS) and mapping were done using the accessory installed in SEM. Nitrogen sorption measurement was determined at $-196^{\circ} \mathrm{C}$ by a micromeritics (QUADRASORB SI, Quantachrome Instruments). The $\mathrm{X}$-ray photoelectron spectroscopy (XPS) was measured with a Thermo Fisher ESCALAB 250Xi spectrometer with a monochromatic $\mathrm{Al} \mathrm{Ka} \mathrm{X}$-ray source. The X-ray diffraction (XRD) patterns of the materials were profiled on a Rigaku D/Max $2500 \mathrm{VB} 2+/ \mathrm{PC}$ X-ray diffractometer using $\mathrm{Cu} K a$ radiation $(\lambda=0.154 \mathrm{~nm})$ with a scan rate of $10^{\circ} \mathrm{min}^{-1}$. Fourier transform infrared (FT-IR) spectroscopy was measured by the Nicolet iS 50 FT-IR analyzer. The metal content of the catalyst was analyzed by using an inductively coupled plasma optical emission spectrometer (ICP-OES, Thermo-Fisher ICAP 6300 Radial). The Raman spectra was performed on the LabRAM ARAMIS with an Ar laser at a wavelength of $514 \mathrm{~nm}$.

\section{Electrochemical measurement}

All electrochemical performances were measured in $0.1 \mathrm{~mol} \mathrm{~L}^{-1} \mathrm{KOH}$ or $0.1 \mathrm{~mol} \mathrm{~L}^{-1} \mathrm{HClO}_{4}$ via an electrochemical workstation system (V3, Princeton Applied 
Research) combined with rotating disk electrode (RDE) or rotating ring-disk electrode (RRDE). The ink dispersions were prepared by dispersing $10 \mathrm{mg}$ of catalysts in a mixture of isopropanol $(800 \mu \mathrm{L})$, deionized water $(200 \mu \mathrm{L})$ and nafion dispersion $(5 \mathrm{wt} \%, 50 \mu \mathrm{L})$. The dispersion was sonicated for $30 \mathrm{~min}$ in ice bath. $10 \mu \mathrm{L}$ of the resulting catalyst ink was then applied onto a rotating disk as a thin film electrode ( $5 \mathrm{~mm}$ diameter, which had already been polished to a mirror using $0.05 \mu \mathrm{m}$ alumina), and the final catalyst loading on electrode was $0.51 \mathrm{mg} \mathrm{cm}$ disk $^{-2}$. As a comparison, $\mathrm{Pt} / \mathrm{C}(20 \mathrm{wt} \%)$ ink was also prepared by dissolving $5 \mathrm{mg} \mathrm{Pt} / \mathrm{C}$ in a mixture consisting of $800 \mu \mathrm{L}$ isopropanol, $200 \mu \mathrm{L}$ water and $10 \mu \mathrm{L}$ nafion dispersion, followed by a same sonication procedure as above. $4 \mu \mathrm{L}$ of the catalyst ink was dropwise added onto the glassy carbon electrode for further study, and the final Pt loading was $20 \mu \mathrm{g}_{\mathrm{Pt}} \mathrm{cm}_{\text {disk }}{ }^{-2}$. A carbon rod and the saturated calomel electrode (SCE) served as the counter electrode and the reference electrode, respectively.

The potentials were converted to the values against reversible hydrogen electrode (RHE). Solution ohmic drop (i.e., $i R$ drop) was compensated. The solution resistance was measured by electrochemical impedance spectroscopy (EIS).

RRDE was used to determine the $\mathrm{H}_{2} \mathrm{O}_{2}$ yield, and the ring electrode was held at $1.3 \mathrm{~V}$ to oxidize $\mathrm{H}_{2} \mathrm{O}_{2}$ diffused from the disk electrode. The electron transfer number $(n)$ and $\mathrm{H}_{2} \mathrm{O}_{2}$ yield of ORR were calculated as following:

$n=\frac{4 I_{\mathrm{d}}}{\left(I_{\mathrm{d}}+I_{\mathrm{r}} / N\right)}$,

$\% \mathrm{H}_{2} \mathrm{O}_{2}=\frac{200\left(I_{\mathrm{r}} / N\right)}{\left(I_{\mathrm{d}}+I_{\mathrm{r}} / N\right)}$,

where $I_{\mathrm{d}}$ is the disk current, $I_{\mathrm{r}}$ is the ring current, and $N$ is the collection efficiency of the ring $(N=0.37)$.

The Koutecky-Levich (K-L) equations were also used to calculate the $n$ (Equations (3-5)):

$\frac{1}{j}=\frac{1}{j_{\mathrm{k}}}+\frac{1}{j_{1}}$,

$\frac{1}{j}=\frac{1}{j_{\mathrm{k}}}+\frac{1}{B \omega^{0.5}}$,

$B=0.62 n F C_{\mathrm{O}_{2}}\left(D_{\mathrm{O}_{2}}\right)^{\frac{2}{3}} v^{-\frac{1}{6}}$,

where $j$ is the measured current density; $j_{\mathrm{k}}$ is the kinetic limiting current density; $j_{1}$ is the limiting current; $B$ is the Levich slope; $F$ is the Faraday constant $\left(96,485 \mathrm{C} \mathrm{mol}^{-1}\right)$; $\omega$ is the rotation speed; $D_{\mathrm{O}_{2}}$ is the $\mathrm{O}_{2}$ diffusion coefficient $\left(1.9 \times 10^{-5} \mathrm{~cm}^{2} \mathrm{~s}^{-1}\right) ; C_{\mathrm{O}_{2}}$ is the $\mathrm{O}_{2}$ bulk concentration $\left(1.2 \times 10^{-3} \mathrm{~mol} \mathrm{~L}^{-1}\right) ; \quad v \quad$ is the electrolyte viscosity $\left(0.01 \mathrm{~cm}^{2} \mathrm{~s}^{-1}\right)$.

\section{PEMFC test}

The MEA was prepared through a spraying and hotpressing method [34]. The cathode catalyst ink was prepared by ultrasonic dispersion of catalyst $(8 \mathrm{mg})$ and $5 \mathrm{wt} \%$ nafion solution ( $100 \mu \mathrm{L}, 38.5 \mathrm{wt} \%$ in catalyst layer) in ice bath for $1 \mathrm{~h}$. The anode ink recipe was $2.1 \mathrm{mg}$ of Pt/ $\mathrm{C}(20 \mathrm{wt} \%, \mathrm{JM}), 21 \mu \mathrm{L}$ of $5 \mathrm{wt} \%$ nafion solution, $200 \mu \mathrm{L}$ of deionized water and $800 \mathrm{~mL}$ of isopropanol. The freshly prepared ink was then transferred to an airbrush supplied by an air compressor. The anode and cathode catalyst layers were carefully sprayed onto the two sides of nafion membrane (NRE 211), respectively. An mask with an open square window $\left(1.0 \times 1.0 \mathrm{~cm}^{2}\right)$ in the centre was placed on the top of the membrane to restrict the active area of MEA. The membrane was heated to $60^{\circ} \mathrm{C}$ during the spaying process to accelerate the evaporation of solvent. The final loading of MEA was $0.2 \mathrm{mg}_{\mathrm{Pt}}$ for anode and $4.0 \mathrm{mg}_{\text {cat }}$ for cathode. Then, the MEA was assembled by hot-pressing the gas diffusion layer (SGL, 28BC, $1.0 \times 1.0 \mathrm{~cm}^{2}$ ) with the catalyst-coated membrane at $5 \mathrm{~kg} \mathrm{~cm}^{-2}$ and temperature of $130^{\circ} \mathrm{C}$ for $90 \mathrm{~s}$. Fuel cell performance of the obtained MEA was tested on a multirange fuel cell test system (850e, Scribner Associates Inc.). The $\mathrm{H}_{2}$ and $\mathrm{O}_{2}$ flow rates were 0.1 slpm at $100 \%$ relative humility (RH) for polarization curve measurement, and $0.05 \mathrm{slpm}$ at $100 \% \mathrm{RH}$ for stability measurement. The cell temperature was $80^{\circ} \mathrm{C}$. A back pressure of 2.0 bar was applied.

\section{RESULTS AND DISCUSSION}

\section{Synthesis and characterization of the biomass converted ORR catalyst}

The synthetic procedure was illustrated in Fig. 1. The black fungus firstly underwent a hydrothermal process for primary carbonization to produce a carbon-enriched precursor [35]. This step can be easily enlarged, and more than $25 \mathrm{~g}$ of precursors could be produced in one batch (Fig. S1). Then it was mixed with urea and $\mathrm{ZnCl}_{2}$, and further pyrolyzed in a nitrogen-rich environment constructed by melamine. We optimized the pyrolysis temperature, and found the best temperature of $950^{\circ} \mathrm{C}$ (the optimization details were discussed later in the catalyst optimization section). We named this product as BF-N950.

Fig. 2a and $\mathrm{c}$ show the TEM and SEM images of the asobtained BF-N-950. An enlarged SEM image is shown in 


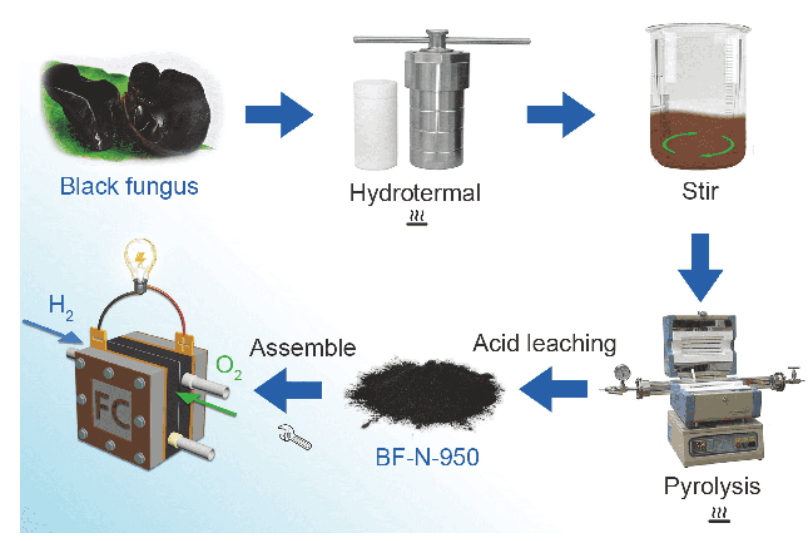

Figure 1 Schematic illustration for the synthesis of BF-N-950 and further fabrication of a PEMFC.

Fig. S2. The nanoparticle size is $50-500 \mathrm{~nm}$ with no well crystallized inorganic nanoparticles, demonstrating the main products are carbon-based materials. Fig. $2 \mathrm{~b}$ shows the high resolution TEM (HRTEM) image of BF-N-950. No clear lattice fringe can be observed, demonstrating the amorphous carbon structure of the BF-N-950. In Fig. 2d$\mathrm{h}$, the EDS elemental mapping images show the even distribution of $\mathrm{C}, \mathrm{N}, \mathrm{S}$ and $\mathrm{Fe}$, demonstrating the black fungus has converted to Fe, N, S-doped carbon material. This composition was previously considered as the promising catalyst for ORR [36,37].

In Fig. 3a, the XRD patterns show the broad peaks at $2 \theta$ $=26.6^{\circ}$ and $43.5^{\circ}$, which can be ascribed to the (002) and (101) planes of graphite. No impurity peak was observed, revealing our method prevented the metallic agglomeration and the formation of inorganic particles during the synthesis.

The surface area and pore structure were studied by nitrogen adsorption-desorption isotherm. The surface area was $916 \mathrm{~m}^{2} \mathrm{~g}^{-1}$ calculated by the Brunauer-EmmettTeller (BET) method. The large specific surface area makes the product expose more active sites. The pore distribution was also calculated and shown in Fig. 3b. It shows the micropores distributed from 1.0 to $2.0 \mathrm{~nm}$. The pores might come from the special structure of the black fungus precursors. Additionally, $\mathrm{ZnCl}_{2}$ was also introduced as the pore-forming agent in our synthesis [38]. $\mathrm{ZnCl}_{2}$ promoted dehydration, charring and aromatization of the precursor, and it helped the formation of pore structure of the products [39]. We also tested the pore distribution of the sample synthesized without adding $\mathrm{ZnCl}_{2}$. The average pore size of the sample without adding $\mathrm{ZnCl}_{2}$ is $0.90 \mathrm{~nm}$, smaller than that of the sample with $\mathrm{ZnCl}_{2}(0.99 \mathrm{~nm})$, confirming that $\mathrm{ZnCl}_{2}$ is beneficial

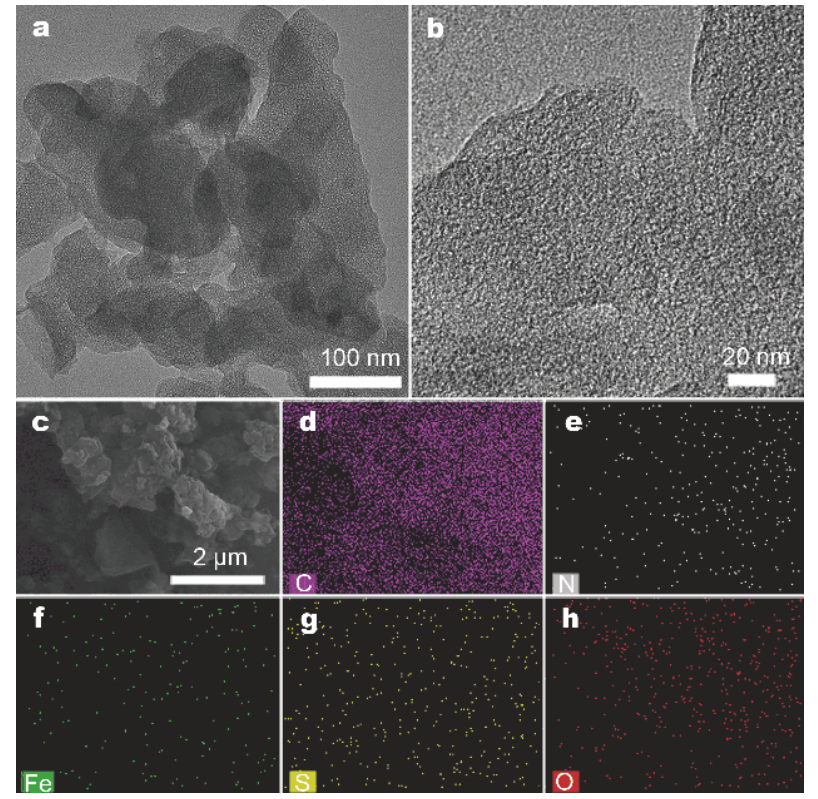

Figure 2 (a) TEM image of the BF-N-950. (b) HRTEM image of the BFN-950. (c-g) SEM image and the corresponding EDS elemental mapping images of the BF-N-950.

to pore generation. The pores contribute to the mass transfer processes, which is important for catalysis $[40,41]$.

\section{Electrochemical evaluation for ORR}

The ORR activity of the BF-N-950 was initially studied by cyclic voltammetry $(\mathrm{CV})$ in both acid and alkaline electrolytes. Compared with the $\mathrm{CV}$ curves in $\mathrm{O}_{2}$-staturated and Ar-saturated electrolytes (Fig. S3), a clear reduction peak appeared when the catalyst was tested in $\mathrm{O}_{2}$-saturated electrode, demonstrating the ability to reduce oxygen. To quantify the ORR activity of the catalysts, RDE method was employed. Fig. $4 \mathrm{a}$ and $\mathrm{b}$ show the polarization curves of the catalysts tested in $\mathrm{O}_{2}$-saturaetd electrolyte with working electrode rotated at $1600 \mathrm{rpm}$. Control samples and commercial $\mathrm{Pt} / \mathrm{C}$ were also tested at the same condition for comparison. Without black fungus or by replacing it with carbon black, the obtained catalysts (named as N-950 and CB-N-950, respectively) show low ORR activity, demonstrating the unique property of the biomass black fungus. When black fungus was used as the precursor for the synthesis of the catalyst (i.e., BF950), the ORR activity was significantly improved. The BF-950 shows the ORR half wave potential $\left(E_{1 / 2}\right)$ of $0.86 \mathrm{~V}$ ( vs. RHE, the same hereafter) in $0.1 \mathrm{~mol} \mathrm{~L}^{-1} \mathrm{KOH}$ and $0.65 \mathrm{~V}$ in $0.1 \mathrm{~mol} \mathrm{~L}^{-1} \mathrm{HClO}_{4}$, reaching a relative high activity, especially in alkaline condition. The improved ORR activity is attributed to the rich $\mathrm{Fe}$ and $\mathrm{N}$ in the 

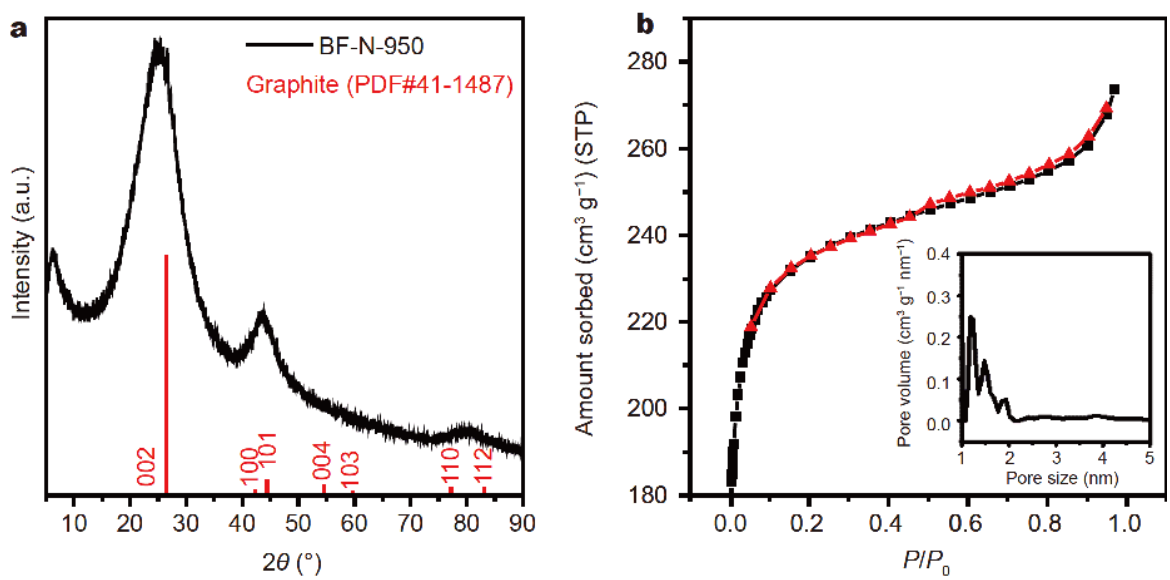

Figure 3 (a) XRD pattern of the BF-N-950. (b) Nitrogen adsorption-desorption isotherms and pore size distribution (insert) profiles of the BF-N-950 catalyst.
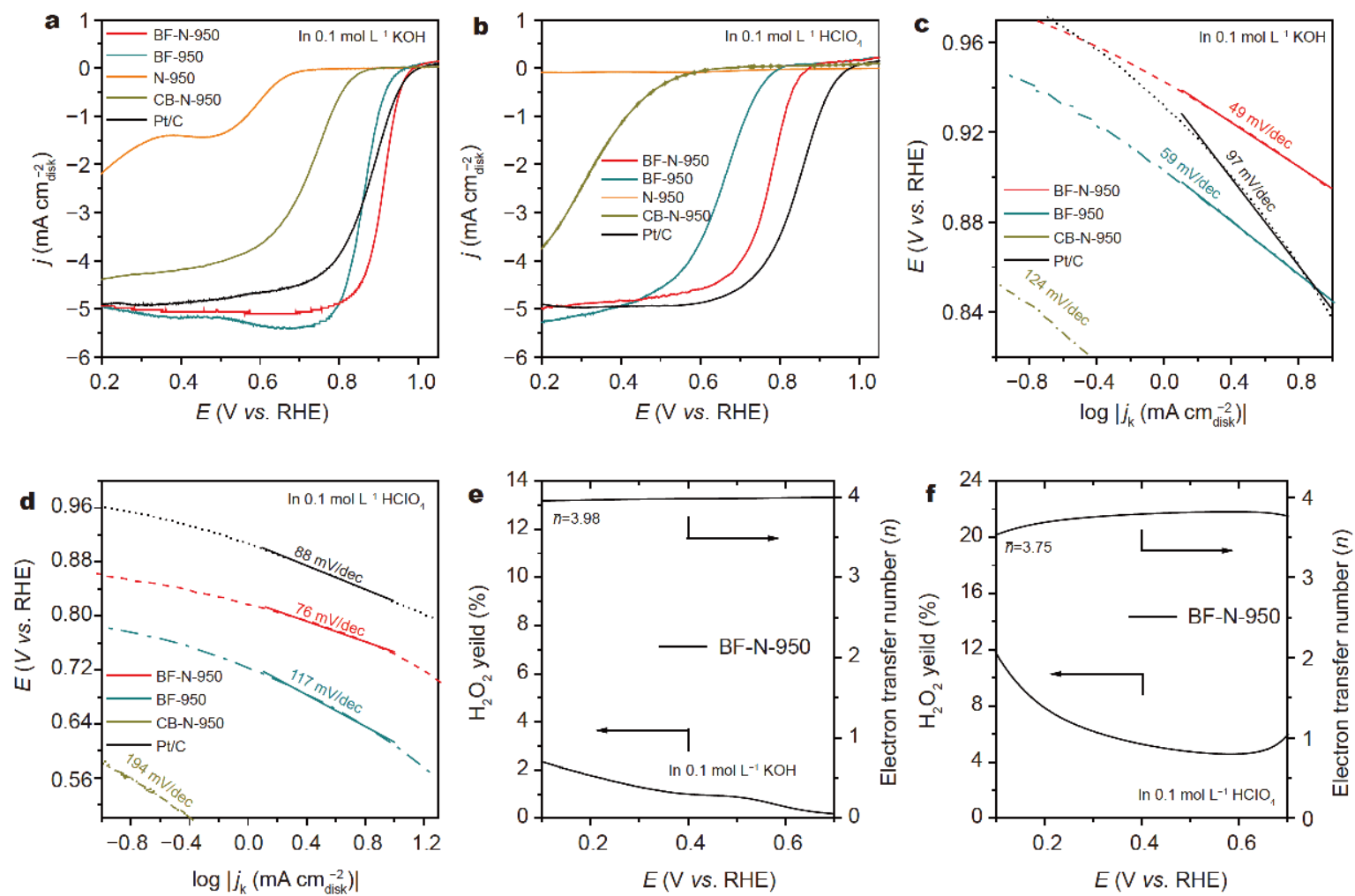

Figure 4 (a) Liner sweep voltammetry (LSV) polarization curves of the catalysts tested in $\mathrm{O}_{2}$-saturated $0.1 \mathrm{~mol} \mathrm{~L}^{-1} \mathrm{KOH}$ at a scan rate of $1 \mathrm{mV} \mathrm{s}^{-1}$. (b) LSV polarization curves of the catalysts tested in $\mathrm{O}_{2}$-saturated $0.1 \mathrm{~mol} \mathrm{~L}^{-1} \mathrm{HClO}_{4}$ at a scan rate of $1 \mathrm{mV} \mathrm{s}^{-1}$. (c) The corresponding Tafel slopes in $0.1 \mathrm{~mol} \mathrm{~L}^{-1} \mathrm{KOH}$. (d) The corresponding Tafel slopes in $0.1 \mathrm{~mol} \mathrm{~L}^{-1} \mathrm{HClO}_{4}$. The $\mathrm{H}_{2} \mathrm{O}_{2}$ yield and electron transfer number of the BF-N-950 in (e) $0.1 \mathrm{~mol} \mathrm{~L}^{-1} \mathrm{KOH}$ and (f) $0.1 \mathrm{~mol} \mathrm{~L}^{-1} \mathrm{HClO}_{4}$.

black fungus, which is beneficial to the formation of ORR active sites on the $\mathrm{Fe}$ and $\mathrm{N}$-doped carbon [8].

The ORR activity could be further improved via introducing additional $\mathrm{N}$ sources. The BF-N-950 sample shows high ORR activity in both acid and alkaline electrolytes. Fig. $4 \mathrm{a}$ and $\mathrm{b}$ show that the BF-N-950 has the $E_{1 / 2}$ of $0.91 \mathrm{~V}$ in $0.1 \mathrm{~mol} \mathrm{~L}^{-1} \mathrm{KOH}$ and $0.77 \mathrm{~V}$ in $0.1 \mathrm{~mol} \mathrm{~L}^{-1}$ $\mathrm{HClO}_{4}$, respectively. The ORR activity of BF-N-950 in 
alkaline electrolyte surpasses that of commercial $\mathrm{Pt} / \mathrm{C}$. The as-obtained BF-N-950 also shows the highest ORR activity compared with the reported biomass-derived ORR catalysts (Table S3), demonstrating that the black fungus is an outstanding resource for producing ORR catalysts. The BF-N-950 also shows a low Tafel slope of $49 \mathrm{mV} / \mathrm{dec}$ in $0.1 \mathrm{~mol} \mathrm{~L}^{-1} \mathrm{KOH}$ and $76 \mathrm{mV} / \mathrm{dec}$ in $0.1 \mathrm{~mol} \mathrm{~L}^{-1} \mathrm{HClO}_{4}$ (Fig. $4 \mathrm{c}$ and d). The ORR polarization curves at different rotation speeds were also recorded, as shown in Figs S4a and S5a. The K-L plots are shown in Figs S4b and S5b, where a linear relationship was found. The electron transfer number was calculated as 3.9 for both alkaline and acid electrolytes, demonstrating the high efficiency to reduce oxygen to water, which was further confirmed by the RRDE measurement (polarization curves and corresponding ring current curves shown in Fig. S6), showing that the as-obtained BF-N-950 catalyst had low $\mathrm{H}_{2} \mathrm{O}_{2}$ yield in both acid and alkaline electrolytes (Fig. $3 e$ and $\mathrm{f}$ ).

The durability of the BF-N-950 was examined. As shown in Fig. S7, the $E_{1 / 2}$ of BF-N-950 drops about $10 \mathrm{mV}$ after $1000 \mathrm{CV}$ cycle sweeps between 0 to $1.1 \mathrm{~V}$ at a scan rate of $50 \mathrm{mV} \mathrm{s}^{-1}$, demonstrating the reasonable stability of the catalyst. We also studied the anti-poisoning ability of BF-N-950 to methanol. Fig. S8 shows the chronoamperometric curve of the catalyst at $0.75 \mathrm{~V}$. After injection of methanol, the current almost did not reduce for the BF-N-950, indicating the high tolerance to the fuels, while the $\mathrm{Pt} / \mathrm{C}$ catalyst almost completely lost its ORR activity after methanol injection.

\section{Catalyst optimization}

We optimized the process for additional $\mathrm{N}$ doping by mixing the precursor with N-rich compounds (such as $\mathrm{NH}_{3}$ and urea), or pyrolyzing the precursor under a N- rich environment (such as in the atmosphere generated by decomposing of melamine) [41,42]. Fig. S9 summarizes the polarization curves of the catalysts obtained by using different $\mathrm{N}$ doping agents and methods. Both two doping methods could promote the ORR. By comparing the ORR activity obtained through different additional $\mathrm{N}$ doping sources (Fig. S10), it was found that pyrolysis under the $\mathrm{N}$-rich environment generated by melamine was the most efficient route, with the highest ORR activity. However, cooperating with both $\mathrm{N}$ doping methods, the obtained BF-N-950 catalyst showed the highest ORR in both acid and alkaline electrolytes. This sample was assumed with the highest $\mathrm{N}$ content, which is beneficial to ORR [41].

The element content and surface chemical condition of the as-prepared BF-N-950 were analyzed by using XPS. The N, Fe and S doping amounts for BF-N-950 were measured as 5.14, 0.13 and $0.17 \mathrm{wt} \%$, respectively. The metal content of $\mathrm{Fe}$ was consistent with the ICP-OES result, which was $0.18 \mathrm{wt} \%$. Fig. 5a shows the high resolution $\mathrm{N}$ 1s spectra, which could be deconvoluted into four peaks with binding energies of 398.3, 399.0, 400.6 and $404.5 \mathrm{eV}$, assigned to pyridinic $\mathrm{N}, \mathrm{Fe}-\mathrm{N}_{x}$, pyrrolic $\mathrm{N}$ and graphitic $\mathrm{N}$, respectively $[43,44]$. It is generally believed that the smallest amount of pyrrolic nitrogen and the largest amount of $\mathrm{Fe}-\mathrm{N}_{x}$ centers in the pyridinic environment constitute efficient active sites for ORR [44]. In the as-obtained BF-N-950, the relative amounts of pyridinic $\mathrm{N}$ and $\mathrm{Fe}-\mathrm{N}_{x}$ were counted in high ratio of $22 \%$ and $10 \%$, respectively. Fig. $5 \mathrm{~b}$ shows the high resolution C 1s spectra. The fitted C 1s peaks located at 284.5, 285.5, 286.5, and $290.1 \mathrm{eV}$ can be assigned to graphitic $\mathrm{sp}^{2}$ carbon, amorphous carbon, $\mathrm{sp}^{2}$ carbon bonded to nitrogen, and $\mathrm{sp}^{2}$ carbon bonded to oxygen, respectively [25]. The $\mathrm{N}$ doping was also investigated by FT-IR with the
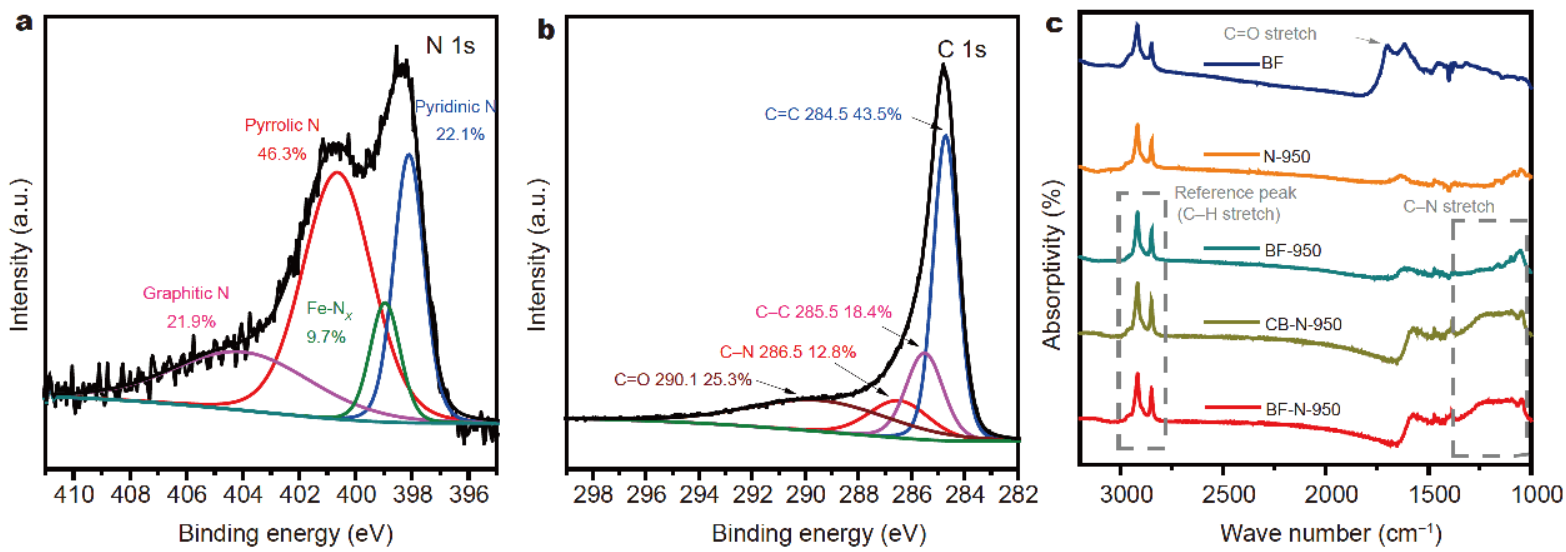

Figure 5 High-resolution N 1s (a) and C 1s (b) XPS spectra of the BF-N-950. (c) FT-IR analysis spectra of the catalysts. 

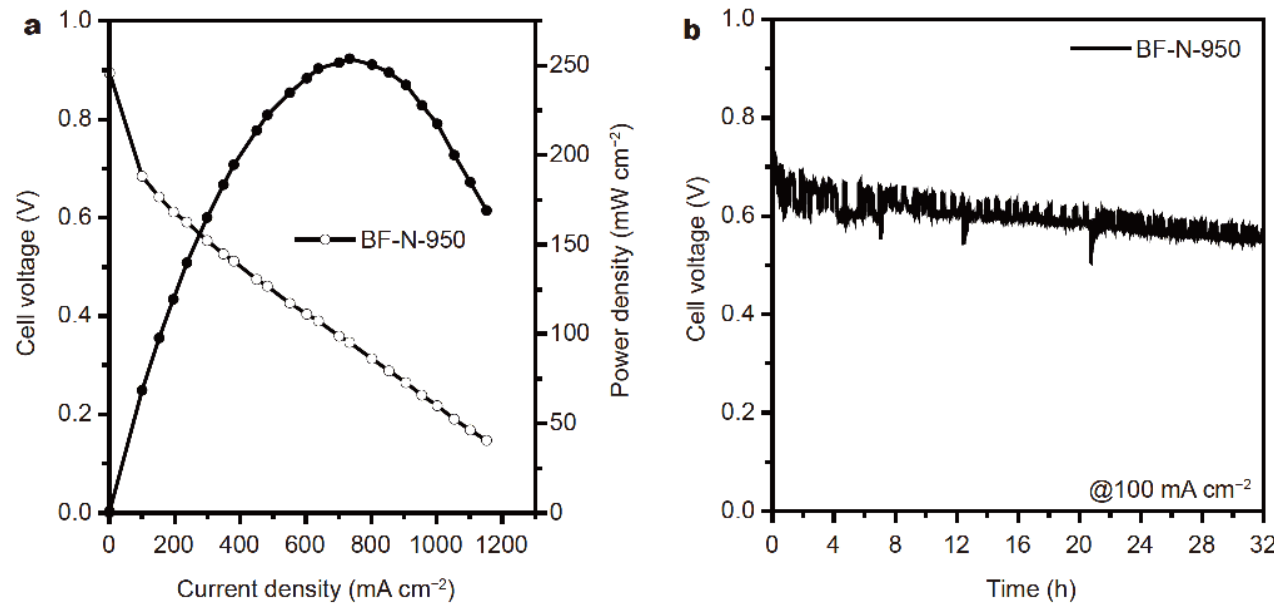

Figure 6 (a) Polarization (open symbols) and the corresponding power density (solid symbols) of the $\mathrm{H}_{2}-\mathrm{O}_{2}$ PEMFC fabricated by using the BF-N950 as cathode catalysts. The cell run at $80^{\circ} \mathrm{C}$. The back-pressure was 2 bar. The $\mathrm{H}_{2}$ and $\mathrm{O}_{2}$ flow rate were both 0.1 slpm. The MEA was assembled by Nafion 211 membrane, the BF-N-950 as cathode catalyst (loading of $\left.4.0 \mathrm{mg} \mathrm{cm}^{-2}\right)$ and Pt/C (20 wt\%) as anode catalyst $\left(\right.$ loading of $\left.0.2 \mathrm{mg}_{\mathrm{Pt}} \mathrm{cm}^{-2}\right)$. The MEA active area was $1.0 \mathrm{~cm}^{2}$. (b) Chronopotentiometric voltage curve of PEMFC using BF-N-950 as cathode at $100 \mathrm{~mA} \mathrm{~cm}$.

characteristic $\mathrm{C}-\mathrm{N}$ stretching vibrations in the range of $1350-1000 \mathrm{~cm}^{-1}$ [45]. We normalized this peak area to the peak area for $\mathrm{C}-\mathrm{H}$ stretching vibration peak in the range of $2750-3000 \mathrm{~cm}^{-1}$, which was considered from the carbon substrate. The value is 1.08, 2.02, 2.23 for BF-950, CB-N-950, BF-N-950, respectively. The BF-N-950 catalyst has the highest $\mathrm{N}$ doping content, which is beneficial to the double doping process.

We also optimized the pyrolysis temperature, and the polarization curves for the catalysts obtained at different temperatures are shown in Fig. S11. It was found $950^{\circ} \mathrm{C}$ was the optimal temperature. Raman spectroscopy was used to analyze the samples prepared at different pyrolysis temperatures (Fig. S12). The peaks at 1580 and $1352 \mathrm{~cm}^{-1}$ are ascribed to the $G$ band and $D$ band of carbons, respectively. The ratio of $I_{\mathrm{D}} / I_{\mathrm{G}}$ increases along with the increase of the pyrolysis temperature, demonstrating more heteroatoms doping in the calcination process [23]. The doped graphite was considered as the active sites for ORR. Thus the higher ORR activity was obtained for the catalyst obtained at pyrolysis temperature of $950^{\circ} \mathrm{C}$.

\section{PEMFC test}

We fabricated a PEMFC by using the as-obtained BF-N950 as the cathode catalyst. MEA was fabricated by using nafion as the membrane, commercial $\mathrm{Pt} / \mathrm{C}$ as the anode and the BF-N-950 as the cathode. Fig. 6a shows the polarization curve and the corresponding power density curve. The MEA shows a high open circuit voltage of ca. $0.9 \mathrm{~V}$. The fuel cell current density is $230 \mathrm{~mA} \mathrm{~cm}^{-2}$ at the cell voltage of $0.6 \mathrm{~V}$, and the cell could deliver a peak power density of $255 \mathrm{~mW} \mathrm{~cm}{ }^{-2}$. The stability of the cell was tested in constant current mode which discharged at a current density of $100 \mathrm{~mA} \mathrm{~cm}^{-2}$. As shown in Fig. 6b, the cell voltage only decreases by $15 \%$ after a continuous operation of $32 \mathrm{~h}$. It is worth to note that the cell performance was not well optimized. Although the cell performance still has a gap to the state-of-the-art PEMFCs [46-48], the low cost and easy accessibility of the raw materials for the BF-N-950 make this catalyst potential in real applications.

\section{CONCLUSIONS}

Low-cost carbon-based ORR catalysts were obtained by using the biomass of black fungus as the raw materials. The synthesized BF-N-950 shows high ORR activity in both acid and alkaline electrolytes. A single PEMFC was fabricated using the as-obtained BF-N-950 as the cathode catalyst, and it showed high cell performance of a peak power density of $255 \mathrm{~mW} \mathrm{~cm}^{-2}$. The high ORR activity was attributed to the rich Fe, N, S, P in the black fungus raw materials and the additional $\mathrm{N}$ doping in the pyrolysis process. These results are significant for developing conversional method for low-cost ORR catalysts, which is promising for the wide application of PEMFCs.

\section{Received 20 October 2019; accepted 24 November 2019; published online 16 December 2019}

1 Ellingsen LAW, Hung CR, Majeau-Bettez G, et al. Nanotechnology for environmentally sustainable electromobility. Nat Nanotech, 2016, 11: 1039-1051 
2 Dai L, Xue Y, Qu L, et al. Metal-free catalysts for oxygen reduction reaction. Chem Rev, 2015, 115: 4823-4892

3 Thompson ST, Papageorgopoulos D. Platinum group metal-free catalysts boost cost competitiveness of fuel cell vehicles. Nat Catal, 2019, 2: 558-561

4 Xiao M, Zhu J, Feng L, et al. Meso/macroporous nitrogen-doped carbon architectures with iron carbide encapsulated in graphitic layers as an efficient and robust catalyst for the oxygen reduction reaction in both acidic and alkaline solutions. Adv Mater, 2015, 27: 2521-2527

5 Wang XX, Swihart MT, Wu G. Achievements, challenges and perspectives on cathode catalysts in proton exchange membrane fuel cells for transportation. Nat Catal, 2019, 2: 578-589

6 Wang S, Yu D, Dai L. Polyelectrolyte functionalized carbon nanotubes as efficient metal-free electrocatalysts for oxygen reduction. J Am Chem Soc, 2011, 133: 5182-5185

7 Meng FL, Wang ZL, Zhong HX, et al. Reactive multifunctional template-induced preparation of $\mathrm{Fe}-\mathrm{N}$-doped mesoporous carbon microspheres towards highly efficient electrocatalysts for oxygen reduction. Adv Mater, 2016, 28: 7948-7955

8 Gewirth AA, Varnell JA, DiAscro AM. Nonprecious metal catalysts for oxygen reduction in heterogeneous aqueous systems. Chem Rev, 2018, 118: 2313-2339

9 Yan D, Guo L, Xie C, et al. N, P-dual doped carbon with trace Co and rich edge sites as highly efficient electrocatalyst for oxygen reduction reaction. Sci China Mater, 2018, 61: 679-685

10 Yang T, Liu J, Zhou R, et al. N-doped mesoporous carbon spheres as the oxygen reduction reaction catalysts. J Mater Chem A, 2014, 2: $18139-18146$

11 Liu Q, Liu X, Zheng L, et al. The solid-phase synthesis of an Fe-N$\mathrm{C}$ electrocatalyst for high-power proton-exchange membrane fuel cells. Angew Chem Int Ed, 2018, 57: 1204-1208

12 Chung HT, Cullen DA, Higgins D, et al. Direct atomic-level insight into the active sites of a high-performance PGM-free ORR catalyst. Science, 2017, 357: 479-484

13 Collman JP, Denisevich P, Konai Y, et al. Electrode catalysis of the four-electron reduction of oxygen to water by dicobalt face-to-face porphyrins. J Am Chem Soc, 1980, 102: 6027-6036

14 Shigehara K, Anson FC. Electrocatalytic activity of three iron porphyrins in the reductions of dioxygen and hydrogen peroxide at graphite electrodes. J Phys Chem, 1982, 86: 2776-2783

15 Okada T. Oxygen reduction characteristics of heat-treated catalysts based on cobalt-porphyrin ion complexes. J Electrochem Soc, 1998, 145: 815-822

16 Jiang R, Tran DT, McClure JP, et al. Ordered mesoporous $\mathrm{FeN}_{x^{-}}$ doped carbon: a class of highly active and stable catalysts in acids, bases and polymer electrolyte membrane fuel cells. J Mater Chem A, 2018, 6: 3941-3953

17 Wu G, More KL, Johnston CM, et al. High-performance electrocatalysts for oxygen reduction derived from polyaniline, iron, and cobalt. Science, 2011, 332: 443-447

18 Jahan M, Bao Q, Loh KP. Electrocatalytically active grapheneporphyrin MOF composite for oxygen reduction reaction. J Am Chem Soc, 2012, 134: 6707-6713

19 Liu YL, Shi CX, Xu XY, et al. Nitrogen-doped hierarchically porous carbon spheres as efficient metal-free electrocatalysts for an oxygen reduction reaction. J Power Sources, 2015, 283: 389-396

20 Yu C, Yuan P, Erickson EM, et al. Oxygen reduction reaction induced $\mathrm{pH}$-responsive chemo-mechanical hydrogel actuators. Soft Matter, 2015, 11: 7953-7959
21 Borghei M, Lehtonen J, Liu L, et al. Advanced biomass-derived electrocatalysts for the oxygen reduction reaction. Adv Mater, 2018, 30: 1703691

22 Dou M, He D, Shao W, et al. Pyrolysis of animal bones with vitamin B12: A facile route to efficient transition metal-nitrogencarbon (TM-N-C) electrocatalysts for oxygen reduction. Chem Eur J, 2016, 22: 2896-2901

23 Chaudhari KN, Song MY, Yu JS. Transforming hair into heteroatom-doped carbon with high surface area. Small, 2014, 10: 2625-2636

24 Song MY, Park HY, Yang DS, et al. Seaweed-derived heteroatomdoped highly porous carbon as an electrocatalyst for the oxygen reduction reaction. ChemSusChem, 2014, 7: 1755-1763

25 Zheng J, Guo C, Chen C, et al. High content of pyridinic- and pyrrolic-nitrogen-modified carbon nanotubes derived from blood biomass for the electrocatalysis of oxygen reduction reaction in alkaline medium. Electrochim Acta, 2015, 168: 386-393

26 Zhang Y, Wang B, Nie A, et al. Carbonaceous photonic crystals prepared by high-temperature/hydrothermal carbonization as high-performance microwave absorbers. J Mater Sci, 2019, 54: 14343-14353

27 Amiinu IS, Zhang J, Kou Z, et al. Self-organized 3D porous graphene dual-doped with biomass-sponsored nitrogen and sulfur for oxygen reduction and evolution. ACS Appl Mater Interfaces, 2016, 8: 29408-29418

28 Guo C, Liao W, Li Z, et al. Easy conversion of protein-rich enoki mushroom biomass to a nitrogen-doped carbon nanomaterial as a promising metal-free catalyst for oxygen reduction reaction. Nanoscale, 2015, 7: 15990-15998

29 Liu Z, Li Z, Tian S, et al. Conversion of peanut biomass into electrocatalysts with vitamin B12 for oxygen reduction reaction in Zn-air battery. Int J Hydrogen Energy, 2019, 44: 11788-11796

30 Liu R, Zhang H, Liu S, et al. Shrimp-shell derived carbon nanodots as carbon and nitrogen sources to fabricate three-dimensional $\mathrm{N}$ doped porous carbon electrocatalysts for the oxygen reduction reaction. Phys Chem Chem Phys, 2016, 18: 4095-4101

31 Zhang Y, Liu X, Wang X, et al. Research progress in the nutritional components and biological activities of Auricularia auricula. South China Agr, 2018, 12: 130-134

32 Zhao J, Guo X, Guo Q, et al. Growth of carbon nanotubes on natural organic precursors by chemical vapor deposition. Carbon, 2011, 49: 2155-2158

33 Feng X, Zhao N, Ze S, et al. Determination of mineral elements in Auriculayia auricular from different habitats. Guizhou Agr Sci, 2016, 44: 35-38

34 Sassin MB, Garsany Y, Gould BD, et al. Fabrication method for laboratory-scale high-performance membrane electrode assemblies for fuel cells. Anal Chem, 2017, 89: 511-518

35 Kambo HS, Dutta A. A comparative review of biochar and hydrochar in terms of production, physico-chemical properties and applications. Renew Sustain Energy Rev, 2015, 45: 359-378

36 Guan Z, Zhang X, Chen W, et al. Mesoporous S doped Fe-N-C materials as highly active oxygen reduction reaction catalyst. Chem Commun, 2018, 54: 12073-12076

37 Zhu Y, Zhang B, Liu X, et al. Unravelling the structure of electrocatalytically active $\mathrm{Fe}-\mathrm{N}$ complexes in carbon for the oxygen reduction reaction. Angew Chem Int Ed, 2014, 53: 10673-10677

38 Hayashi J', Kazehaya A, Muroyama K, et al. Preparation of activated carbon from lignin by chemical activation. Carbon, 2000, 38: 1873-1878 
39 Caturla F, Molina-Sabio M, Rodríguez-Reinoso F. Preparation of activated carbon by chemical activation with $\mathrm{ZnCl}_{2}$. Carbon, 1991, 29: 999-1007

40 Zhang G, Jin X, Li H, et al. N-doped crumpled graphene: bottomup synthesis and its superior oxygen reduction performance. Sci China Mater, 2016, 59: 337-347

41 Shen W, Fan W. Nitrogen-containing porous carbons: synthesis and application. J Mater Chem A, 2013, 1: 999-1013

42 Tian M, Zhu Y, Zhang D, et al. Pyrrolic-nitrogen-rich biomassderived catalyst for sustainable degradation of organic pollutant via a self-powered electro-Fenton process. Nano Energy, 2019, 64: 103940

43 Biddinger EJ, von Deak D, Ozkan US. Nitrogen-containing carbon nanostructures as oxygen-reduction catalysts. Top Catal, 2009, 52: 1566-1574

44 Artyushkova K, Serov A, Rojas-Carbonell S, et al. Chemistry of multitudinous active sites for oxygen reduction reaction in transition metal-nitrogen-carbon electrocatalysts. J Phys Chem C, 2015, 119: 25917-25928

45 Wei J, Hing P, Mo ZQ. TEM, XPS and FTIR characterization of sputtered carbon nitride films. Surf Interface Anal, 1999, 28: 208211

46 Wan X, Liu X, Li Y, et al. Fe-N-C electrocatalyst with dense active sites and efficient mass transport for high-performance proton exchange membrane fuel cells. Nat Catal, 2019, 2: 259-268

47 Wang YC, Lai YJ, Song L, et al. S-doping of an Fe/N/C ORR catalyst for polymer electrolyte membrane fuel cells with high power density. Angew Chem Int Ed, 2015, 54: 9907-9910

48 Wang T, Wang J, Wang X, et al. Graphene-templated synthesis of sandwich-like porous carbon nanosheets for efficient oxygen reduction reaction in both alkaline and acidic media. Sci China Mater, 2018, 61: 915-925

Acknowledgements This work was financially supported by the National Key Research and Development Program of China (2017YFA0206500), the National Natural Science Foundation of China (21671014), and the Fundamental Research Funds for the Central Universities (buctrc201823).

Author contributions Wang X, Zhu W and Zhuang Z conceived and designed the experiments. Wang $X$ performed the synthesis of catalyst and the test of the fuel cell. Wang X, Fang J, Liu X, Zhang X, Lv Q and $\mathrm{Xu} \mathrm{Z}$ characterized the materials and discussed the results of the experiments. Wang $\mathrm{X}$ and Zhuang $\mathrm{Z}$ wrote the paper. All authors participated in the general discussion.

Conflict of interest The authors declare no conflict of interest.

Supplementary information Experimental details and supporting data are available in the online version of the paper.

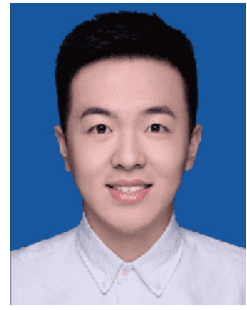

Xingdong Wang is now a graduate student at Beijing University of Chemical Technology under the supervision of Prof. Zhongbin Zhuang. His research interest focuses on the non-precious metal-based catalysts and their application in proton exchange membrane fuel cell.

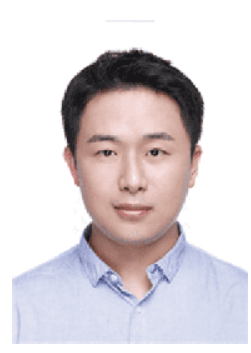

Wei Zhu received his $\mathrm{PhD}$ degree from Peking University in 2014. After postdoctoral work at Tsinghua University, he joined Beijing University of Chemical Technology as an associate professor in 2018. His main research interests lie in the controllable synthesis of functional nanocatalysts, experimental study of nano-electrocatalytic mechanism, and application exploration of nanomaterials in newly developed electrolyser devices.

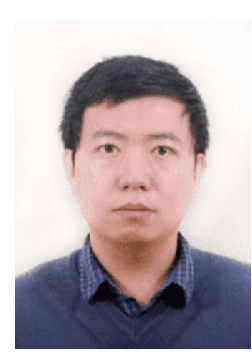

Zhongbin Zhuang received his $\mathrm{PhD}$ degree from Tsinghua University in 2010. After postdoctoral work at the University of California, Riverside and University of Delaware, he joined Beijing University of Chemical Technology as a professor in 2015. His current research interests include electrocatalysts for fuel cell and electrolysers, interfacial electrochemistry and methodology for nanocrystal synthesis.

\section{利用生物质材料合成高性能氢氧燃料电池氧还原 催化剂}

王兴栋, 方锦杰, 刘雪瑞, 张向前, 吕青青, 许照祥, 张雪江, 朱威, 庄仲滨

摘要 制备廉价、高活性氧还原催化剂对于发展氢氧燃料电池清 洁能源极为重要. 在本论文中, 我们利用黑木耳作为生物质材料, 通 过一种便捷的方法合成了高活性氧还原催化剂. 黑木耳经水热和 热解两个步骤, 碳化形成BF-N-950催化剂. 该催化剂在酸性和碱性 溶液中的半波电势分别为 0.77 和 $0.91 \mathrm{~V}$. 采用BF-N-950催化剂作为 膜电极得到的氢氧燃料单电池, 峰值功率可达 $255 \mathrm{~mW} \mathrm{~cm}{ }^{-2}$. 本文 提出了使用生物质材料合成高性能氧还原催化剂的方法, 为氢氧 燃料电池的应用提供了有益探索. 